\section{Enteropathy-associated T-cell lymphoma: involvement of the gastrointestinal tract from the duodenum to the rectum}

Enteropathy-associated T-cell lymphoma (EATL) is a rare type of non-Hodgkin's lymphoma that is commonly associated with celiac disease. The disease is very aggressive with a poor prognosis, and no standardized treatment protocol has been established [1]. An early diagnosis and effec- tive therapy may not be achieved because of the nonspecific clinical and endoscopic findings [2]. The radiologic features of the disease include wall thickening, ulceration, and perforation of the jejunum [3]. ${ }^{18} \mathrm{~F}$-fluorodeoxyglucose $\left({ }^{18} \mathrm{~F}-\mathrm{FDG}\right)$ positron emission tomography/computed to- mography is a useful tool for the staging, management, and prognostication of T-cell lymphoma [4]. Here, we present a unique case of EATL with diffuse involvement of the intestine and colon. A 41-year-old woman was admitted to the hospital with abdominal pain and vomiting in September 2014. Her medical history included celiac disease. Free intraabdominal fluid and liver heterogeneity were detected by ultrasound. Computed tomography revealed multiple hypodense lesions without contrast enhancement in the liver and contrast-enhanced nodularity, which supported the diagnosis of peri-
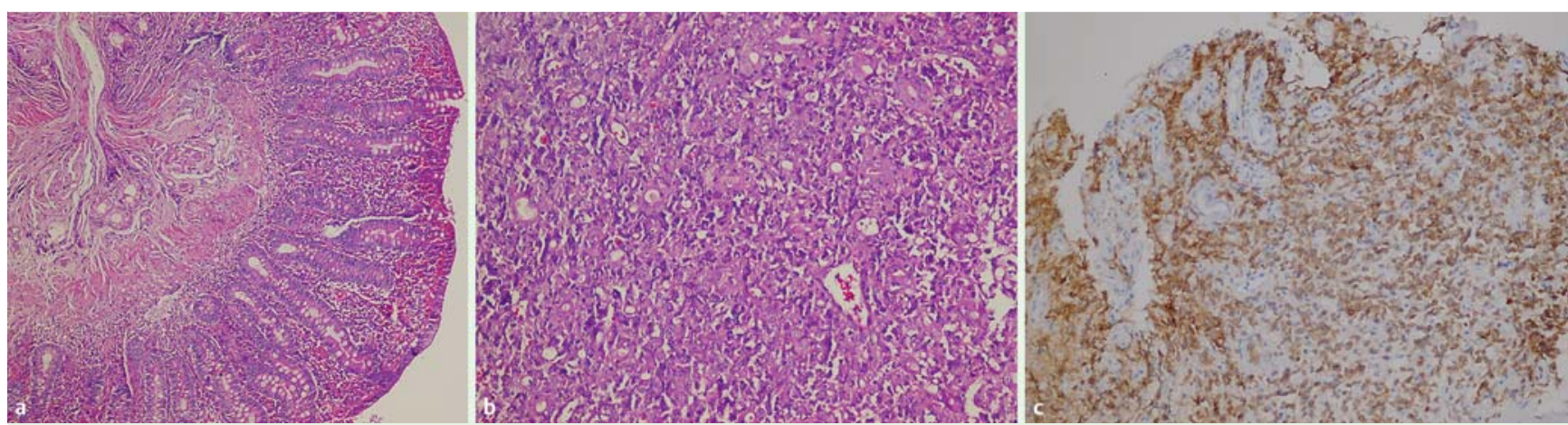

Fig. 1 Histopathologic findings in a 41-year-old woman with enteropathy-associated T-cell lymphoma (EATL). a Celiac disease. Non-neoplastic mucosa distant from an intestinal T-cell lymphoma shows villous atrophy, crypt hyperplasia, and an increase in cytologically unremarkable intraepithelial lymphocytes without evidence of lymphoma (hematoxylin and eosin [H\&E] stain, original magnification $\times 100$ ). b EATL shows ulcerated neoplastic colonic mucosa with infiltrating atypical lymphocytes. The tumor cells are medium to large transformed lymphoid cells with round or angulated vesicular nuclei, prominent nucleoli, and moderate pale-staining cytoplasm between colonic glands (H\&E stain, original magnification $\times 200$ ). c EATL atypical lymphocytes are positive for CD3 (immunohistochemical stain, original magnification $\times 200$ ).
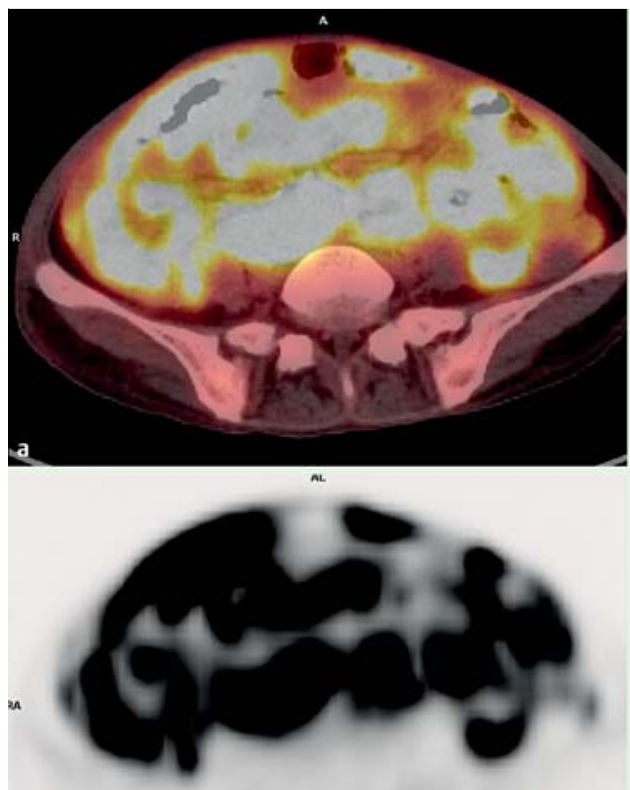

b

Fig. 2 Positron emission tomography/computed tomography (PET/CT) images. Axial PET/CT fusion (a), axial PET (b), and sagittal (c) and coronal (d) PET/CT fusion images. e Maximum-intensity projection image shows diffuse involvement of the entire gastrointestinal tract from the duodenum to the rectum with a high rate of ${ }^{18} \mathrm{~F}$-fluorodeoxyglucose $\left({ }^{18} \mathrm{~F}\right.$-FDG) uptake and enlargement of the intestinal wall. ${ }^{18} \mathrm{~F}$-FDG was evident in and around the liver. 

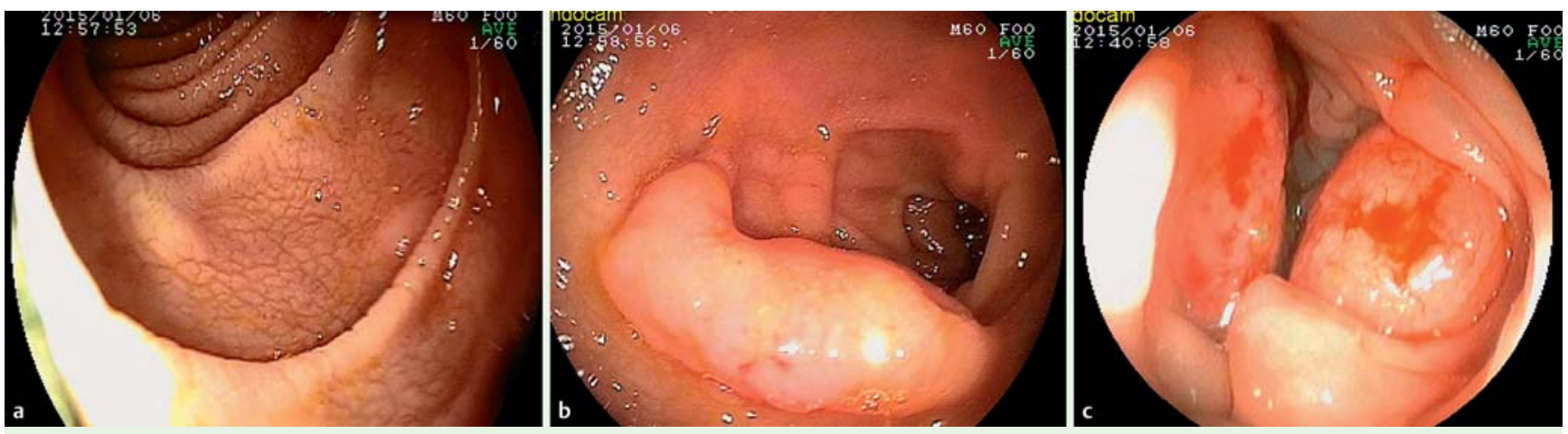

Fig. 3 Endoscopic appearance. a Mucosa with scalloped folds and a mosaic appearance. $\mathbf{b}$ Nodular lesion in the duodenum. c Colonoscopic image of two lesions in the colon.

tonitis carcinomatosa. The results of endoscopy and rectoscopy were compatible with gluten enteropathy. Owing to her worsening clinical condition, the patient underwent laparoscopy, which revealed multiple nodular peritoneal lesions. A biopsy revealed EATL ( $\bullet$ Fig. 1 ).

${ }^{18} \mathrm{~F}-\mathrm{FDG}$ positron emission tomography/ computed tomography performed for staging showed wall thickening in the gastrointestinal tract and intense FDG uptake, beginning in the duodenum and extending to the rectum ( $\bullet$ Fig. 2 ). In addition, nodularity and a high rate of ${ }^{18} \mathrm{~F}-\mathrm{FDG}$ uptake were detected at peritoneal sites, and FDG uptake was increased in and around the liver. Repeat endoscopy and colonoscopy showed multiple nodular lesions in the duodenum and various locations within the colon ( Fig.3). The patient died 1 month after the initiation of chemotherapy.

\section{Endoscopy_UCTN_Code_CCL_1AC_2AZ}

Competing interests: None
Yusuf Demir ${ }^{1}$, Şehmus Ölmez ${ }^{2}$,

Erdem Sürücc̈̈ ${ }^{1}$, Cengiz Demir ${ }^{3}$, Funda Çalışkan Șenköy ${ }^{4}$, irfan Bayram ${ }^{4}$

${ }^{1}$ Yüzüncü Yıl University, School of Medicine, Department of Nuclear Medicine, Van, Turkey

2 Yüzüncü Yıl University, School of Medicine, Department of Gastroenterology, Van, Turkey

${ }^{3}$ Yüzüncü Yıl University, School of Medicine, Department of Hematology,

Van, Turkey

${ }^{4}$ Yüzüncü Yıl University, School of Medicine, Department of Pathology, Van, Turkey

\section{References}

1 Nijeboer P, de Baaij LR, Visser $O$ et al. Treatment response in enteropathy-associated T-cell lymphoma; survival in a large multicenter cohort. Am J Hematol 2015. DOI: 10.1002/ajh.23992. Epub 2015 Feb 25

2 Petrich AM, Helenowski IB, Bryan LJ et al. Factors predicting survival in peripheral T-cell lymphoma in the USA: a population-based analysis of 8802 patients in the modern era. Br J Haematol 2015; 168: 708 - 718

3 Lewis RB, Mehrotra AK, Rodríguez $P$ et al. From the radiologic pathology archives: gastrointestinal lymphoma: radiologic and pathologic findings. Radiographics 2014; 34: 1934-1953

4 Casulo C, Schöder H, Feeney J et al. 18F-Fluorodeoxyglucose positron emission tomography in the staging and prognosis of $\mathrm{T}$ cell lymphoma. Leuk Lymphoma 2013; 54: $2163-2167$

\section{Bibliography}

DOI http://dx.doi.org/

10.1055/s-0034-1392321

Endoscopy 2015; 47: E325-E326

(c) Georg Thieme Verlag KG

Stuttgart · New York

ISSN 0013-726X

\section{Corresponding author} Yusuf Demir, MD

Yüzüncü Yıl University

School of Medicine

Department of Nuclear Medicine

Van

Turkey

Fax: +90-432-486-54-13

dryusufdemir@gmail.com 